\title{
Multiscale Collaborative Optimization of Processing Parameters for Carbon Fiber/Epoxy Laminates Fabricated by High-Speed Automated Fiber Placement
}

\author{
Zhenyu Han, Shouzheng Sun, Zhongxi Shao, and Hongya Fu \\ School of Mechatronics Engineering, Harbin Institute of Technology, No. 92, Xidazhi Street, Harbin 150001, China \\ Correspondence should be addressed to Hongya Fu; hongyafu@hit.edu.cn
}

Received 20 June 2016; Revised 7 October 2016; Accepted 25 October 2016

Academic Editor: Luciano Lamberti

Copyright ( 2016 Zhenyu Han et al. This is an open access article distributed under the Creative Commons Attribution License, which permits unrestricted use, distribution, and reproduction in any medium, provided the original work is properly cited.

Processing optimization is an important means to inhibit manufacturing defects efficiently. However, processing optimization used by experiments or macroscopic theories in high-speed automated fiber placement (AFP) suffers from some restrictions, because multiscale effect of laying tows and their manufacturing defects could not be considered. In this paper, processing parameters, including compaction force, laying speed, and preheating temperature, are optimized by multiscale collaborative optimization in AFP process. Firstly, rational model between cracks and strain energy is revealed in order that the formative possibility of cracks could be assessed by using strain energy or its density. Following that, an antisequential hierarchical multiscale collaborative optimization method is presented to resolve multiscale effect of structure and mechanical properties for laying tows or cracks in high-speed automated fiber placement process. According to the above method and taking carbon fiber/epoxy tow as an example, multiscale mechanical properties of laying tow under different processing parameters are investigated through simulation, which includes recoverable strain energy (ALLSE) of macroscale, strain energy density (SED) of mesoscale, and interface absorbability and matrix fluidity of microscale. Finally, response surface method (RSM) is used to optimize the processing parameters. Two groups of processing parameters, which have higher desirability, are obtained to achieve the purpose of multiscale collaborative optimization.

\section{Introduction}

Carbon fiber/epoxy laminates, due to the advantages of low density, high specific strength, and antifatigue ability, are attractive in a wide array of aerospace fields, where they are especially suitable to design the light-weight aircraft [1]. Automated fiber placement (AFP) is traditionally used on complex surfaces, smaller structures, which utilizes single or multiple narrow, slit tapes or tows to make up a given total prepreg band width. Their productivity is 5-20 times higher than manual fiber placement or semi-AFP [2]. How to guarantee the better production quality is focused on in rapid manufacturing at present. Some advanced AFP machines are produced by MAG CINCINNATI, INGERSOLL, and MTORRES, which have the ultimate laying speed of about $50-60 \mathrm{~m} / \mathrm{min}$ and compaction force of about $0.8 \mathrm{MPa}$. Most of laying speed is in the range of $10-20 \mathrm{~m} / \mathrm{min}$ [3]. We consider that the high-speed mentioned refers to laying speed greater than $20 \mathrm{~m} / \mathrm{min}$ in AFP process.

More manufacturing defects are driven at high-speed manufacturing process than low-speed due to higher energy accumulation in rapid manufacturing process. Generally, inhibition of manufacturing defects can be beneficial to improving the laying quality. However, the formations of manufacturing defects, which could have impact on the performance of entire laminate structure, have multiscale effect. More specifically, microdefects of carbon fiber/epoxy laminates or laying prepreg tow are triggered under the manufacturing loads, preheating temperature, and environment. Furthermore, the expansion and convergence of microdefects could result in bigger or macroscopic manufacturing defects under continuous loads. For example, the microcracks could be extended to the entire fiber/matrix interface, which is a "long" creep process, and it includes different spatiotemporal 
scales [4]. This statement also works from the physical point of view that cracks form at the atomic scale, extend to the macroscopic level, are irreversible, and travel far from equilibrium [5]. However, the multiscale material damage still remains a compelling challenge until now [6-10]. Although much research has been done on the defects of composites during service life [11-13], little work has been done on the evolution mechanism of multiscale defects in AFP process.

The processing parameters optimization can offer a way to diminish the manufacturing defects that occur during AFP process. Grouve et al. [14] investigated the interrelation between processing parameters, material properties, and interlaminar bond strength. Experiments demonstrated that an excellent bond quality can be obtained at high velocities and low input power in case the laser is primarily aimed at the tape. Tumkor et al. [15] established the model of thermoplastic tape lay-up in terms of heat transfer and investigated the effects of processing parameters on the quality of thermoplastic composite laminates fabricated by tape placement. Sonmez and Akbulut [16] adopted two objectives to optimize processing parameters. One was to minimize the peak of tensile residual stress. The other was to increase the productivity by maximizing the laying speed. Aized and Shirinzadeh [17] analyzed and optimized robotic fiber placement processing parameters using response surface method. However, most of the publications performed processing parameter optimization based on macromechanics or experiments, which suffered from some limitations that neglected the multiscale effect in optimization process.

There are three main processing parameters in AFP process. One is compaction force that plays the role of increasing the interfacial adsorption ability and reducing bubbles. The second is laying speed, which could control the productivity and motion paths of AFP process. The last is preheating temperature which has a most important function of increasing the fluidity of the resin. The aim of this paper is to optimize the processing parameters of AFP collaboratively based on mechanical properties of different scales. In macroscopic and mesoscopic scale, ALLSE and SED are investigated to assess the probability of the formation of crack defects through building a relational model between cracks and strain energy. Then the energy transfer model is established to import energy from macro-/mesoscale to microscale based on homogenization method. Further, adsorption energy (AE) and diffusion coefficient (DC) of microscopic region are calculated to reveal the characteristics of interface absorbability and matrix fluidity. Four objectives of optimization are separately considered, of which the first two are to minimize the peak of ALLSE and SED, and the others are to maximize the AE and DC. Finally, two groups of processing parameters, which allow for multiscale effect of defects, are optimized by RSM.

\section{Relational Model between Cracks and Strain Energy}

The microcracks are induced by a high residual tensile stress in high-speed AFP process because of different thermal expansion coefficient between fiber and matrix [18]. The increase of stress would result in the increase of length and quantity of cracks under continuous loads, and finally microcracks become the macroscopic cracks (i.e., interfiber failure, IFF) through entire tow. Thus microcracks are the baseline form of many manufacturing defects. For example, crack-tips tend to follow the high stress concentration, which may cause partial delamination defect. Similarly, Puck and Schürmann [19] studied the relationship between IFF and delamination using some experiments. The results show that as long as the phenomenon of IFF cracks does not occur in composite laminate structure, the delamination cannot be driven. It follows that optimized processing parameters for inhibition of microcracks should be able to reduce other manufacturing defects effectively. So it is important to establish defect model of cracks, which could assess the probability of the formation of microcracks by some physical quantities or parameters.

In this study, the method of damage mechanics is used to reveal relationship between microcracks and strain energy. In Figure 1, microcracks are distributed along a direction $(\alpha)$ uniformly within the laying tow in high-speed AFP process. A feature unit $\mathrm{d} V(1)$ is shown in Figure 1:

$$
\mathrm{d} V=\mathrm{d} x \mathrm{~d} y \mathrm{~d} h,
$$

where $h$ is the thickness of laying tow.

The presence of $N$ microcracks within the feature unit is assumed, and the area of each of the microcracks is designated as $S_{m}(m=1,2, \ldots, N)$. The strain energy of the feature unit is calculated by

$$
U\left(S_{1}, S_{2}, \ldots, S_{m}\right)=U(0)+\sum_{m=1}^{N} \int_{0}^{S_{m}} \frac{\partial U}{\partial S_{m}} \mathrm{~d} S_{m} .
$$

Each cracks is assumed to have an equal area. There is

$$
S_{m}=2 a h,
$$

where $a$ is half-crack length.

The function of strain energy density is gained in

$$
u=u^{0}+2 n \int_{0}^{a} \frac{\partial U}{\partial a} \mathrm{~d} a
$$

where $n$ is crack density.

The function of initial strain energy density is showed as

$$
u^{0}=\frac{1}{2} C_{i j k l} \varepsilon_{i j} \varepsilon_{k l} \text {, }
$$

where $C_{i j k l}$ is stiffness tensor and $\varepsilon_{i j}$ and $\varepsilon_{k l}$ are strain tensor $(i, j, r, s=1,2,6)$.

In the case of crack propagation along the direction of crack plane, the releasing of potential energy $U_{g}$ is expressed as

$$
U_{g}=\frac{\mathrm{d} U}{\mathrm{~d} a}=D_{1} K_{1}^{2}+D_{2} K_{2}^{2} .
$$




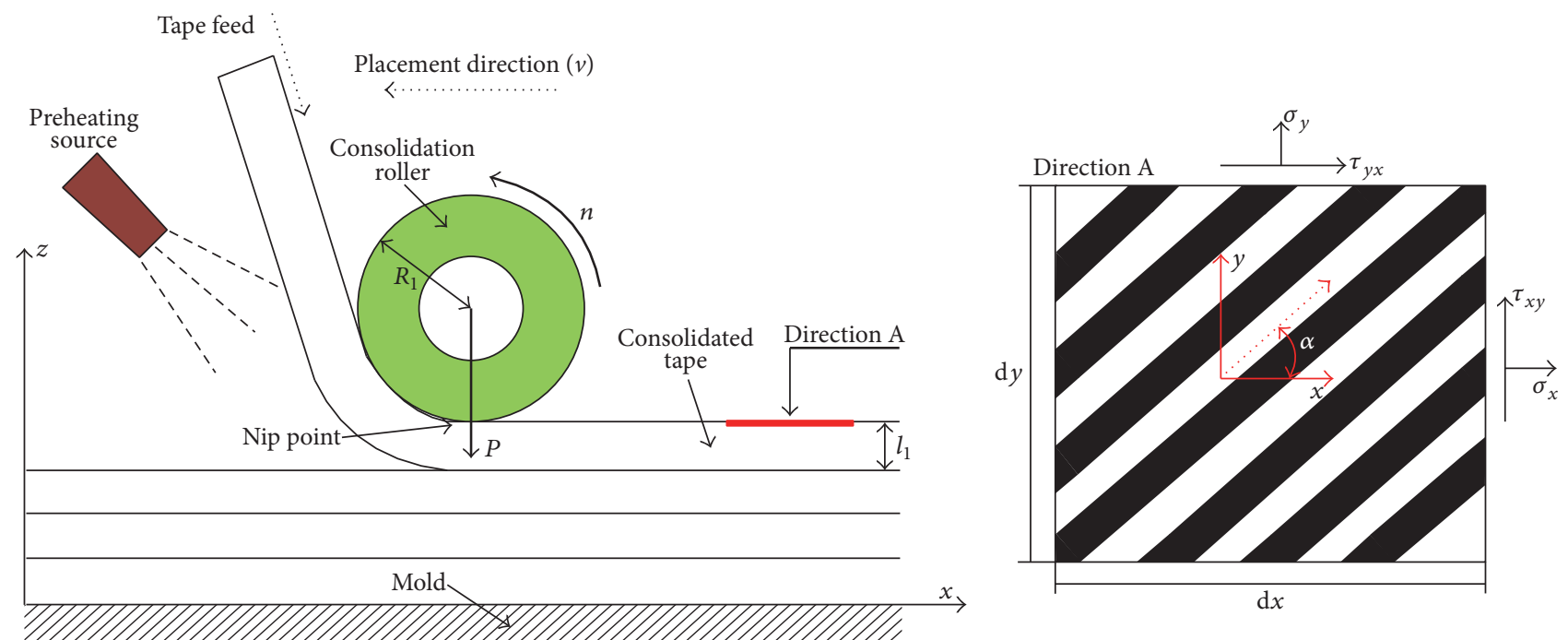

FIGURE 1: High-speed preheating AFP process and a feature unit.

The material constants $D_{1}$ and $D_{2}$ are calculated by (7) for the orthotropic materials:

$$
\begin{aligned}
& D_{1}=\sqrt{\frac{e_{11} e_{22}}{2}}\left(\sqrt{\frac{e_{22}}{e_{11}}}+\frac{2 e_{12}+e_{66}}{2 e_{11}}\right)^{1 / 2}, \\
& D_{2}=\frac{e_{11}}{\sqrt{2}}\left(\sqrt{\frac{e_{22}}{e_{11}}}+\frac{2 e_{12}+e_{66}}{2 e_{11}}\right)^{1 / 2},
\end{aligned}
$$

where $e_{i j}$ is flexibility coefficient in the main direction of material, $i, j=1,2,6$.

Tensile stress intensity factor $K_{1}$ and shear stress intensity factor $K_{2}$ are shown in

$$
\begin{aligned}
& K_{1}=\sigma \sqrt{\pi a} R_{1}(a, n), \\
& K_{2}=\tau \sqrt{\pi a} R_{2}(a, n),
\end{aligned}
$$

where $\sigma$ is tensile stress in crack plane, $\tau$ is shear stress in crack plane, $R_{1}$ is interaction factor of tensile crack, and $R_{2}$ is interaction factor of shear crack.

On the basis of (4)-(8), the function of strain energy density becomes

$$
\begin{aligned}
u & =u^{0}+2 \pi n \int_{0}^{a}\left[D_{1} \sigma^{2} R_{1}^{2}(a, n)+D_{2} \tau^{2} R_{2}^{2}(a, n)\right] a \mathrm{~d} a \\
& =u^{0}+B\left(\sqrt{e_{11} e_{22}} \sigma^{2} \omega_{1}+e_{11} \tau^{2} \omega_{2}\right) .
\end{aligned}
$$

In (9), $\omega_{1}$ is tensile damage variable, $\omega_{2}$ is shear damage variable, and $B$ is a constant. Their specific algorithms are shown in

$$
\omega_{1}=\int_{0}^{a} R_{1}^{2}(a, n) n 2 \pi a \mathrm{~d} a
$$

$$
\begin{aligned}
& \omega_{2}=\int_{0}^{a} R_{2}^{2}(a, n) n 2 \pi a \mathrm{~d} a \\
& B=\frac{1}{\sqrt{2}}\left(\sqrt{\frac{e_{22}}{e_{11}}}+\frac{2 e_{12}+e_{66}}{2 e_{11}}\right)^{1 / 2} .
\end{aligned}
$$

Strain energy density can be expressed as a function of processing parameters such as compaction force, laying speed, and preheating temperature, which are shown in

$$
u=u^{0}+f(F, S, T) \text {. }
$$

$u^{0}=0$ is assumed. And, according to (9), correlation among damage variable $\omega$ and stress and processing parameters is revealed in

$$
f(F, S, T)=B\left(\sqrt{e_{11} e_{22}} \sigma^{2} \omega_{1}+e_{11} \tau^{2} \omega_{2}\right) .
$$

Flexibility coefficients are constants because the same composite prepreg is adopted. So $B$ is a constant. $\sigma$ and $\tau$ are closely associated with $\omega_{1}$ and $\omega_{2}$. Equation (12) shows that processing parameters could cause the internal stress of the composite to change and then lead to the formation of damage. ALLSE and SED are physical quantities which could evaluate intensity and distribution of stress. Hence, ALLSE and SED are changed with different processing parameters. Also, (4), (9), and (12) show that the formation and expansion of microcracks have a positive relationship with the strain energy and its density that vary with the processing parameters in high-speed AFP process. Therefore, the evolution trend of ALLSE and SED can be investigated to assess the probability of formation of microcracks under different processing parameters.

\section{Multiscale Optimization Method}

The thickness of prepreg tow is about $100 \sim 200 \mu \mathrm{m}$, which belongs to a mesoscopic level; however, the length and width 


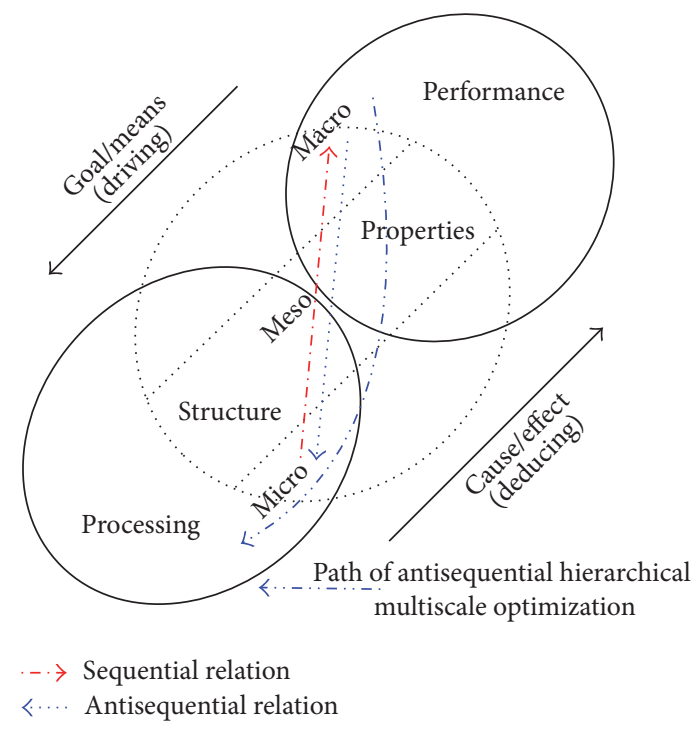

FIGURE 2: Antisequential hierarchical multiscale relationship.

of prepreg tow are greater than $1 \mathrm{~mm}$ which belong to a macroscopic level. Due to distinctive structure of prepreg tow, a concurrent analysis method can be applied to study the macromesoscopic mechanical properties [20]. The concurrent analysis method regards the macroscale and mesoscale as a homogenization large-scale based on the homogenization method. Sequential multiscale analysis method is usually used to calculate large-scale physical parameters based on the analytical results of smaller scale [21,22], while the boundary conditions of small-scale are difficult to be determined in the manufacturing process. To solve the above-mentioned problem, an antisequential analysis model is presented to arrive at the fact that small-scale parameters can be determined by analytical results of large-scale. It is beneficial to build the relational model among micromechanical properties, macromesoscopic properties, and processing parameters. The hierarchical relationship of materials design has been developed by Olson [23]. In this paper, the hierarchical thought is extended to design and optimize the processing parameters of AFP. The antisequential hierarchical multiscale relationship is portrayed in Figure 2.

According to the antisequential multiscale analysis method and Olson theory, an antisequential hierarchical multiscale collaborative optimization method (Figure 3) for AFP process is presented, which includes the homogenization method, concurrent/sequential multiscale analysis, hierarchical model of material design, and energy transfer model of multiscale and RSM. This method is applicable for bandshape structure of prepreg.

In Figure 3, macroscopic and microscopic analyses are executed using the concurrent multiscale analysis method, which include the establishment of finite element method (FEM) model and the calculation of ALLSE and SED. Then energy transfer model needs to be established to input energy from macromesosystem to microsystem homogeneously. Furthermore, an antisequential analysis method is used to obtain the boundary conditions of microsystem based on the analytical results of macromesosystem. Interface absorbability and matrix fluidity in the microsystem are assessed by $\mathrm{AE}$ and DC. Finally, RSM is adopted to optimize the processing parameters with multiscale mechanical properties. Therefore, optimized processing parameters could achieve multiscale effect collaboratively, which provides great potential for minimizing the possibility of the formation of crack defects.

\section{Simulation Experiments}

\subsection{Macromesoscale}

4.1.1. Materials and FEM Model. In this paper, optimal processing parameter is obtained by using the proposed antisequential hierarchical multiscale collaborative optimization method, which utilizes FEM, molecular dynamics (MD) simulation, and RSM. First of all, ALLSE and SED of laying tow in macromesoscale should be calculated by FEM. Then boundary conditions of FEM for prepreg tow are set up, wherein mechanical properties of a carbon fiber/epoxy prepreg are exhibited in Table 1, where E1, E2, and E3 are the modulus of elasticity in the $x, y$, and $z$ directions, respectively ( $x$ is the length direction of tow, $y$ is the width direction of tow, and $z$ is the vertical direction). $v 12, v 13$, and $v 23$ are Poisson's ratio in different planes ( $x y, x z$, and $y z$ planes, resp.). G12, G13, and $G 23$ are the shear modulus in different planes ( $x y, x z$, and $y z$ planes, resp.).

FEM model which includes roller, prepreg tow, and laminates in high-speed AFP is established by using Abaqus. Laying speed is set as $27 \mathrm{~m} / \mathrm{min}, 30 \mathrm{~m} / \mathrm{min}, 33 \mathrm{~m} / \mathrm{min}$, and $36 \mathrm{~m} / \mathrm{min}$, respectively, and compaction force is considered to be $150 \mathrm{kPa}, 200 \mathrm{kPa}, 250 \mathrm{kPa}$, and $300 \mathrm{kPa}$, respectively. The levels of laying speed and compaction force are crosslinked, respectively; thus 16 groups of boundary conditions could be obtained. In this study, simulation time is set to be $125 \mu \mathrm{s}$. The bottom of laminates, which are formed by 4 unidirectional layers, is fully constrained. In addition, the actual length of lay-up tow is $280 \mathrm{~mm}$, and contact type is set as rough between the laying tow and the laminates. To analyze the mesomechanical characteristics of a unit in the laying tow, number 175 mesh is chosen to serve as an analytical object (Figure 4), which could also be regarded as a feature mesounit in Figure 1.

Stress distribution of entire model and laminates is obtained under different processing parameters, wherein laying speed of $36 \mathrm{~m} / \mathrm{min}$ and compaction force of $150 \mathrm{kPa}$ are shown in Figure 5.

4.1.2. Macroscopic Characteristics (ALLSE). The curves of ALLSE in time domain (Figure 6) are calculated to reveal the relationship between processing parameters and laying quality directly, as well as showing the probability of the formation of microcracks in the laying tow indirectly.

From Figure 6, it also can be seen that ALLSE have higher peak and intense oscillation mostly in the later period of AFP, which probably is because the accumulation of energy cannot easily be released due to the same tow length with a shorter rolling time. On the basis of the results of ALLSE, a range of laying speed of about $30-36 \mathrm{~m} / \mathrm{min}$ and compaction force of 
TABLE 1: Mechanical properties of a bisphenol A epoxy matrix prepreg.

\begin{tabular}{lcccccc}
\hline Density & $E 1$ & $E 2, E 3$ & $v 12, v 13$ & $v 23$ & $G 12, G 13$ & $G 23$ \\
\hline $1.49 \mathrm{~g} / \mathrm{cm}^{3}$ & $121 \mathrm{GPa}$ & $8.6 \mathrm{GPa}$ & 0.27 & 0.4 & $4.7 \mathrm{GPa}$ & $3.1 \mathrm{GPa}$ \\
\hline
\end{tabular}

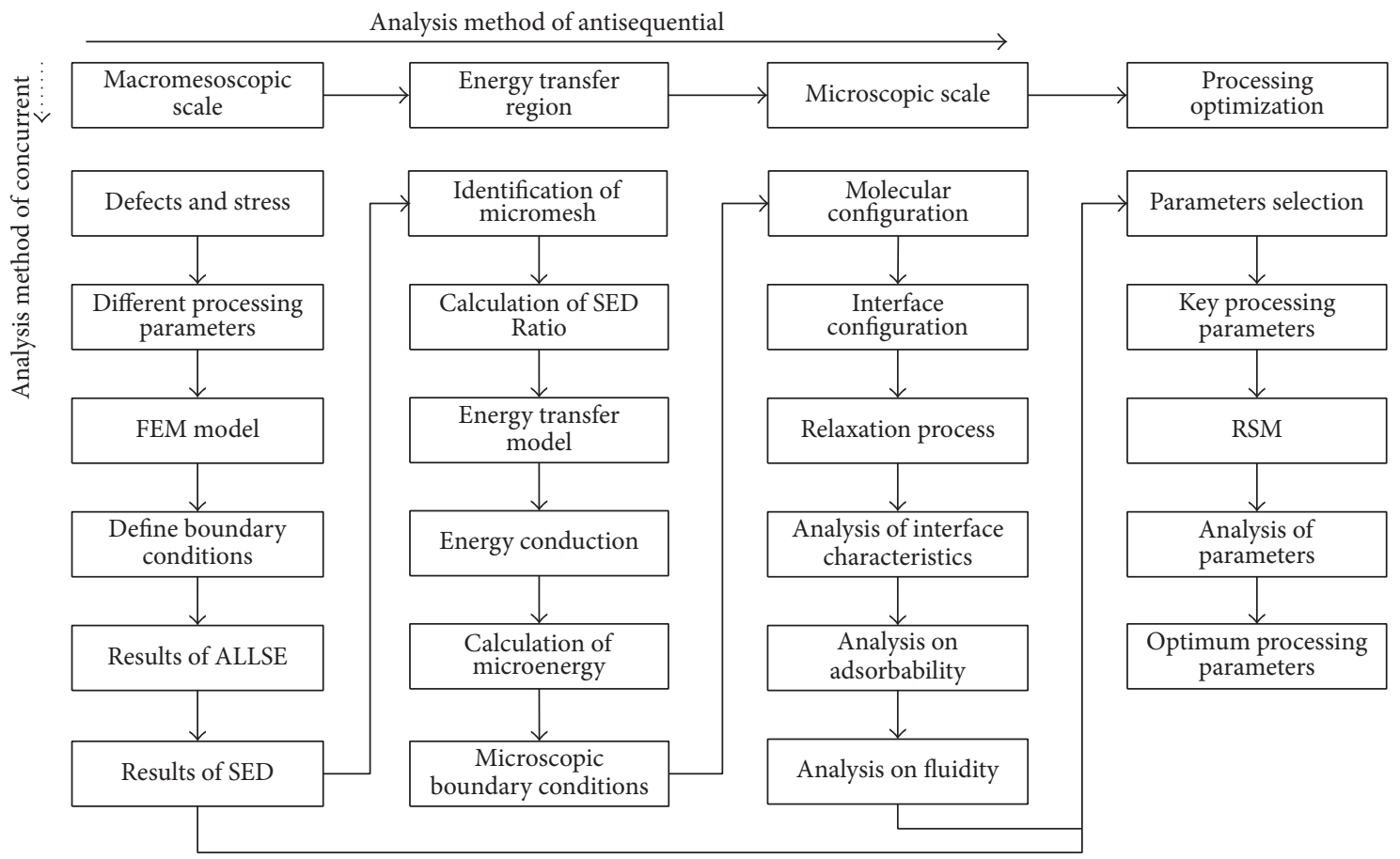

FIgURE 3: Antisequential hierarchical multiscale collaborative optimization method of processing parameters.

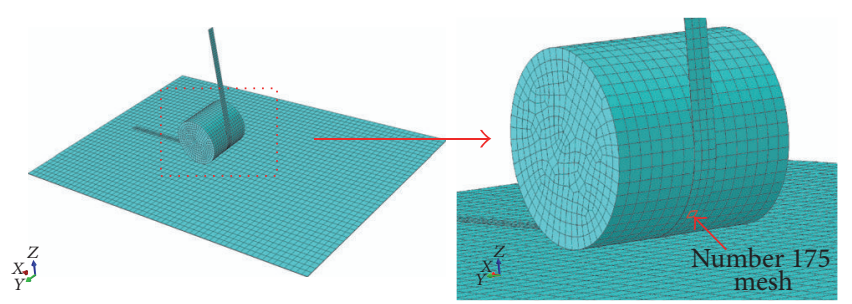

FIGURE 4: FEM model and position of number 175 mesh in highspeed AFP process.

$300 \mathrm{kPa}$ are preferred, which shows a lower peak and stable curves of ALLSE.

4.1.3. Mesoscopic Characteristics (SED in Number 175 Mesh). Number 175 mesh is compressed by roller directly which is an important feature mesounit in rolling region. The curves of SED in number 175 mesh are calculated as shown in Figure 7.

In Figure 7, most curves of SED show intense oscillation under different processing parameters because of propagation of stress waves irregularly. The distance from the beginning of rolling to the ending of rolling through a unit is called roll nip of unit here. In most cases, the peaks of SED in number 175 mesh are not within time domain of roll nip, because the transmission, convergence and accumulation of stress waves are not easily released at higher level of energy. Therefore, the phenomenon usually occurs in highspeed manufacturing. Most curves of SED present an abrupt decreasing in correspondence of a laying speed of $36 \mathrm{~m} / \mathrm{min}$. It is explained that strain energy is not easy to accumulate in higher laying speed because higher laying speed could lead to shorter roll nip time. According to the stability analysis of SED curves in number 175 mesh, compaction force of $200 \mathrm{kPa}$ is a more suitable processing parameter.

4.2. Energy Transfer Model. The accuracy of energy transfer (ET) region model is crucial to accomplishing the calculation of multiscale. There are two difficulties. One is the incoordination of constitutive relation between FEM region and MD region, and the other is adverse effect of the incoordination on energy wave transfer. MADD method (i.e., macroscopic, atomistic, ab initio dynamics) [24] could be known as the origin of the calculation of atomic engineering, which has the combination of tight-binding method, FEM, and MD. Quantum, atomic, and macroscopic scales are calculated simultaneously by the MADD method, but its drawback is that the design of ET region cannot take the reflection of energy waves into consideration. If so, the reflected energy is reserved in FEM region or MD region, even making the regions melt away as a whole [25]. Focusing on the problem, one-dimensional model [26], Cauchy-Born rule, multiscale analytical method, and quasi continuous multiscale analysis 


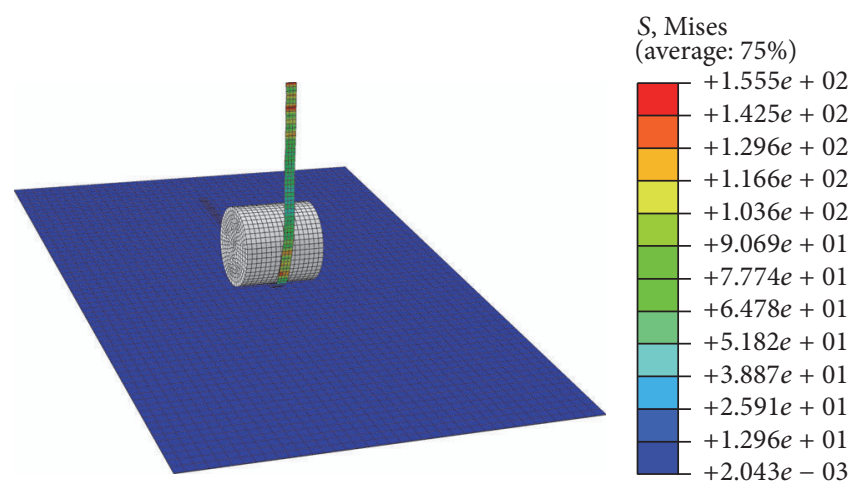

(a)

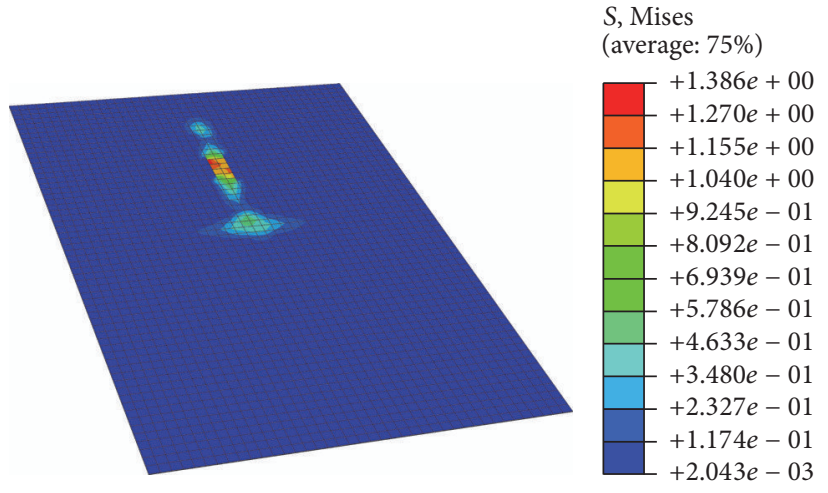

(b)

FIGURE 5: Stress distribution of FEM model with laying speed of $36 \mathrm{~m} / \mathrm{min}$ and compaction force of $150 \mathrm{kPa}$ : (a) the entire model; (b) the laminates.

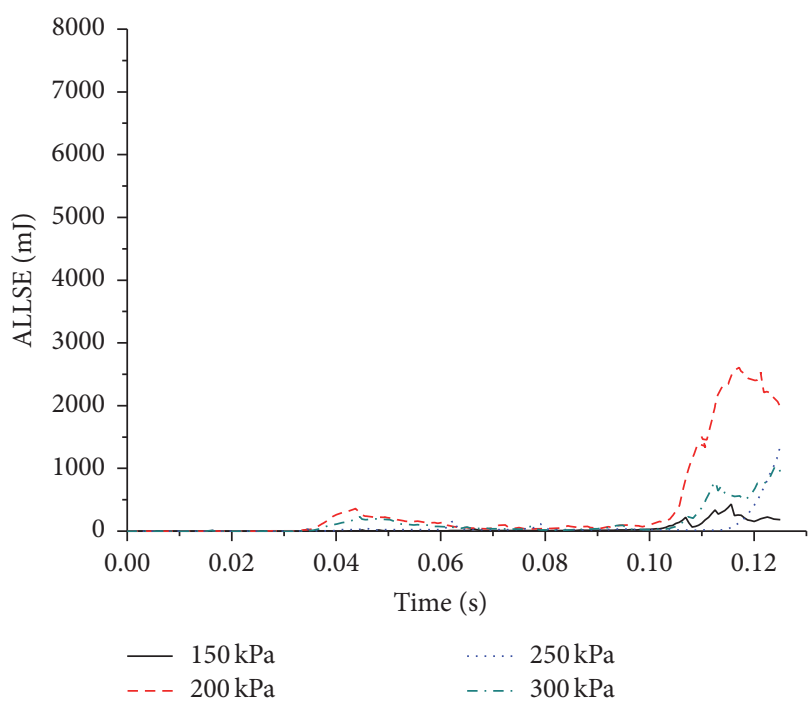

(a)

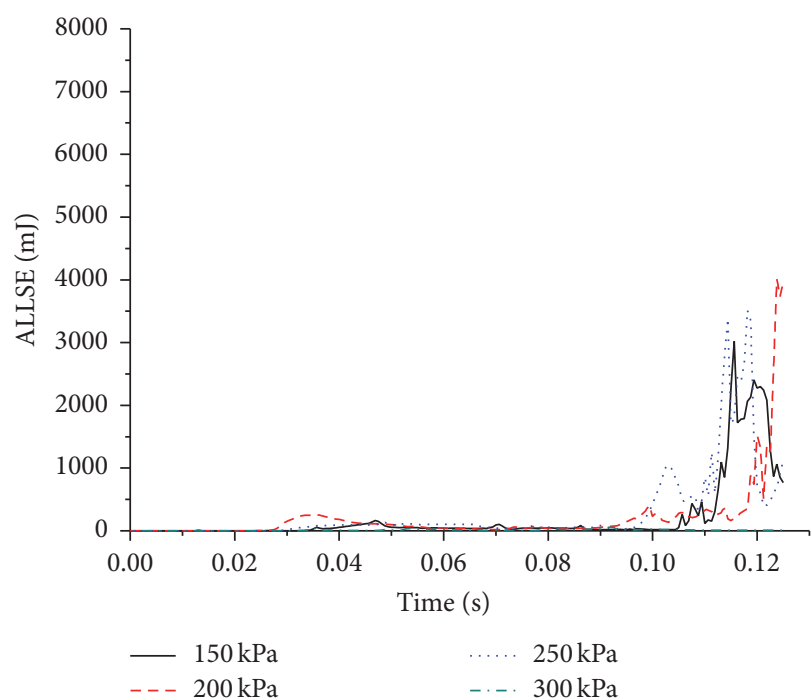

(c)

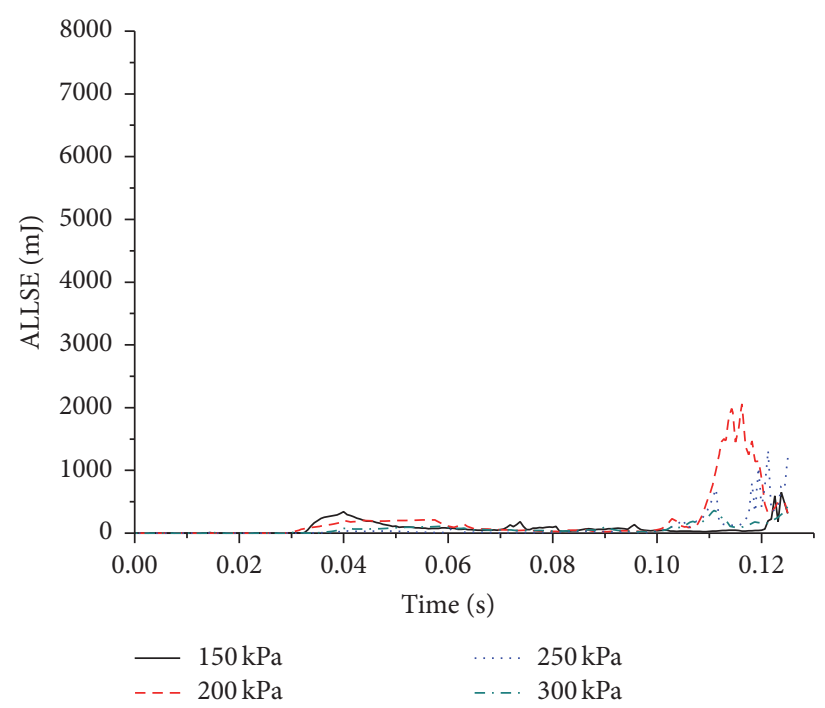

(b)

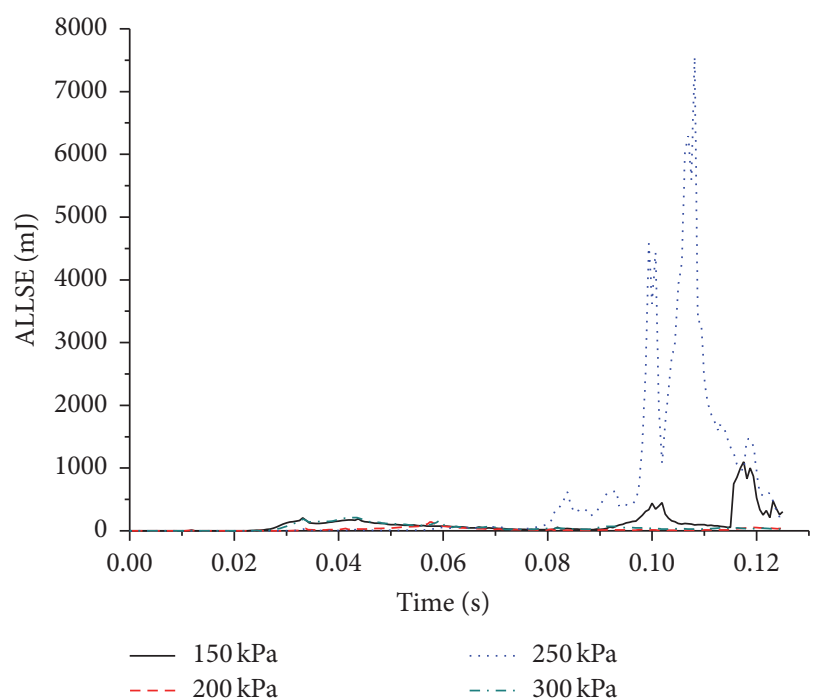

(d)

FIGURE 6: Curves of ALLSE under different processing parameters in AFP process: (a) laying speed of $27 \mathrm{~m} / \mathrm{min}$; (b) laying speed of $30 \mathrm{~m} / \mathrm{min}$; (c) laying speed of $33 \mathrm{~m} / \mathrm{min}$; (d) laying speed of $36 \mathrm{~m} / \mathrm{min}$. 


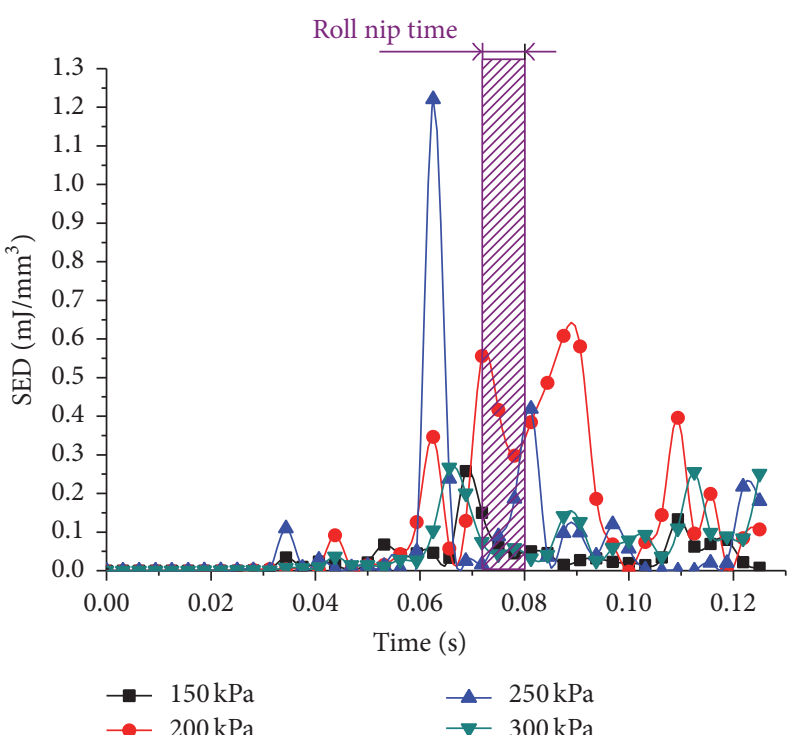

(a)

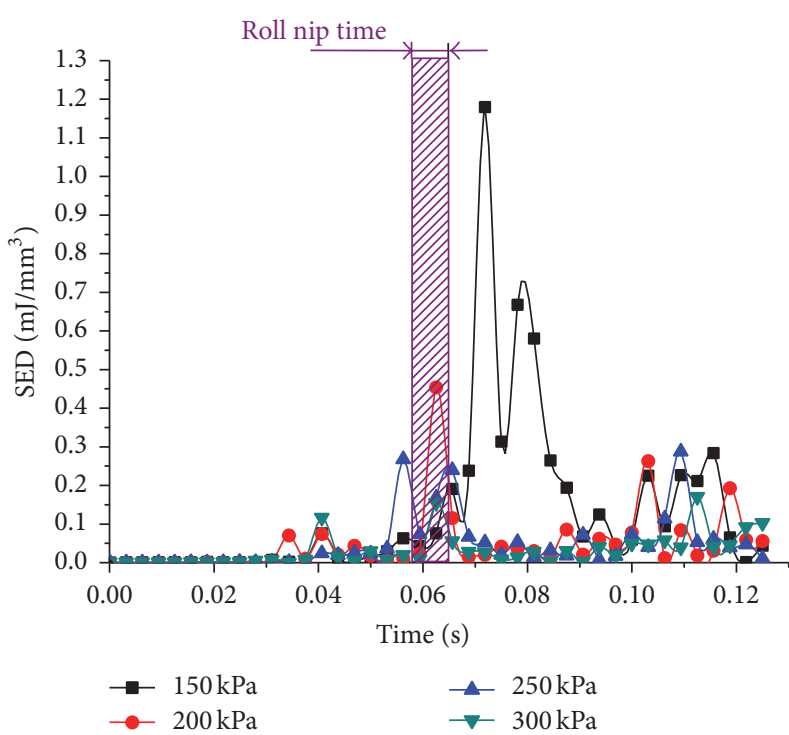

(c)

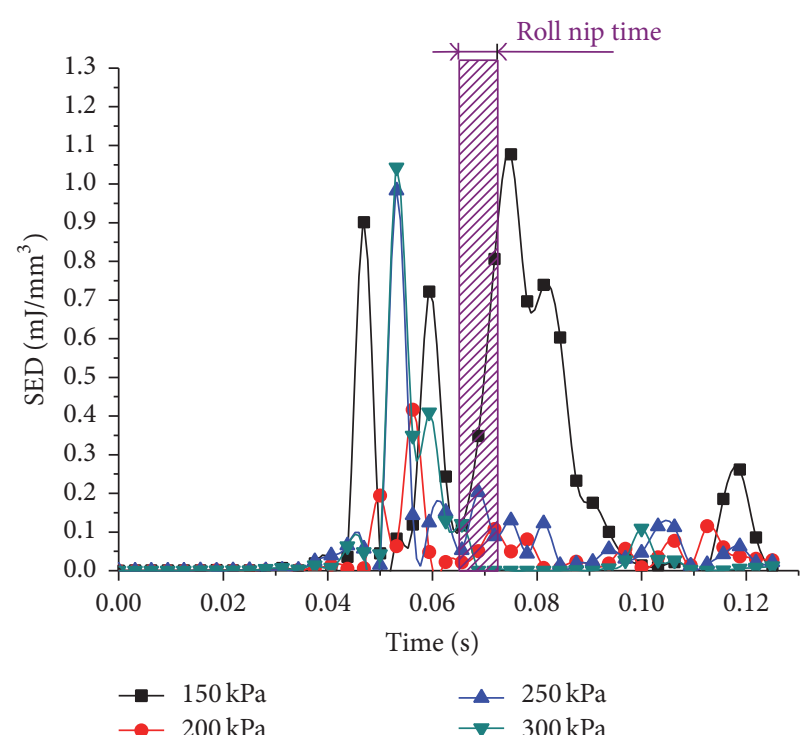

(b)

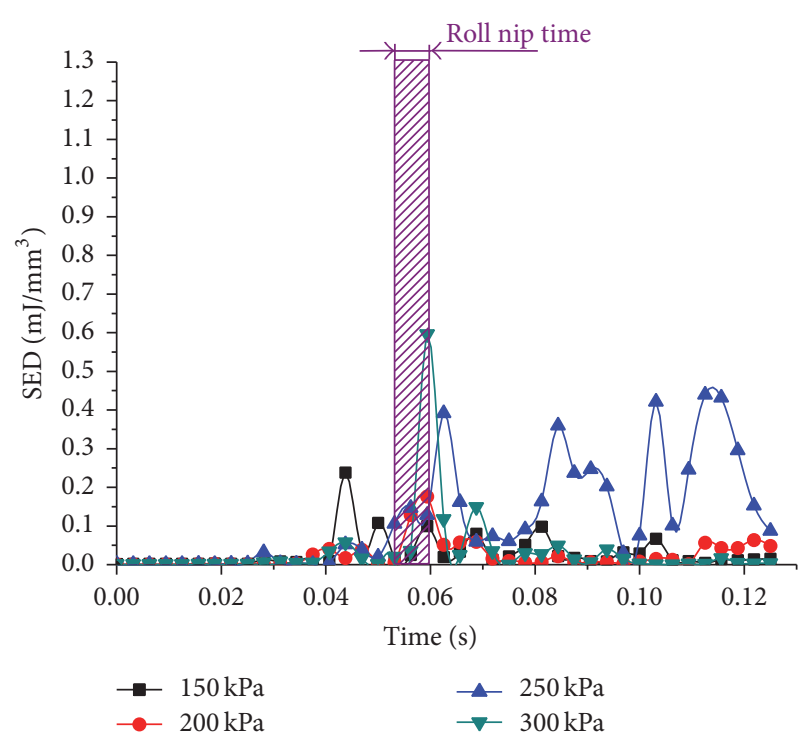

(d)

FIGURE 7: Curves of SED in number 175 mesh under different processing parameters in AFP process: (a) laying speed of $27 \mathrm{~m} / \mathrm{min}$; (b) laying speed of $30 \mathrm{~m} / \mathrm{min}$; (c) laying speed of $33 \mathrm{~m} / \mathrm{min}$; (d) laying speed of $36 \mathrm{~m} / \mathrm{min}$.

method (QC) [27] were developed. However, these methods are only applicable for certain special situations. Also, most of these methods cannot solve three-dimensional problems. First of all, the construction of energy within region of different scales should be found out. Based on expression of the MADD method, the total system consists of FEM region, $\mathrm{MD}$ region, and ET region. Their energy expression is given by

$$
\begin{aligned}
u_{\mathrm{tot}} & =u_{\mathrm{FEM}}+u_{\mathrm{MD}}+u_{\mathrm{FEM} / \mathrm{MD}} \\
& =\left(\omega_{\mathrm{FEM}}+1\right) \sum_{i=1}^{n} u_{i}+\left(\omega_{\mathrm{MD}}+1\right) \sum_{j=1}^{m} u_{j}^{\prime},
\end{aligned}
$$

where $u_{\text {tot }}$ is the total energy of system, $u_{\mathrm{FEM}}$ is the energy in FEM region, $u_{\mathrm{MD}}$ is the energy in MD region, $u_{\mathrm{FEM} / \mathrm{MD}}$ is the energy in ET region, $\omega_{\mathrm{FEM}}$ and $\omega_{\mathrm{MD}}$ are weighting factors, $u_{i}$ is the energy of a mesh, $n$ is the number of mesh in FEM region, $u_{j}^{\prime}$ is the energy of a microscopic system, and $m$ is the number of microscopic system in MD region.

A design method of ET region is presented to achieve the homogeneous transfer of energy based on homogenization method and MADD method. Homogeneous distribution of volumetric energy of a mesomesh is assumed to establish the scaling of strain energy as (14) which makes strain energy input from FEM region to $\mathrm{MD}$ region. The design of ET region is shown in Figure 8:

$$
u_{c m}^{\prime}=\frac{V_{c m}}{V} u_{c n}
$$




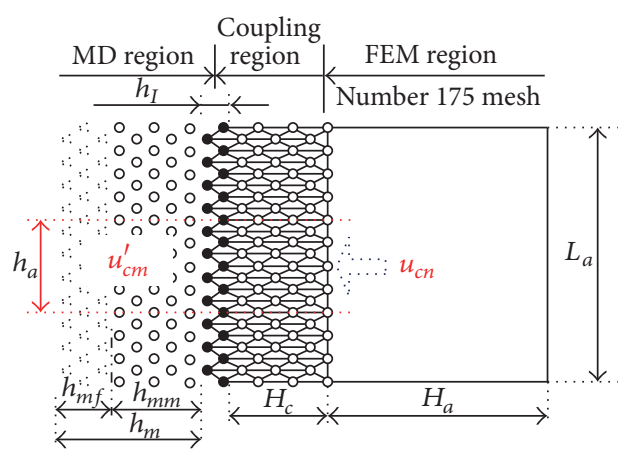

FIGURE 8: The design for ET region of FEM/MD and the process of energy transfer.

where $u_{c m}^{\prime}$ is the strain energy in the microsystem, $V_{c m}$ is the volume of microsystem, $u_{c n}$ is the strain energy of a mesh, and $V$ is the volume of the mesh.

In Figure $8, h_{a}$ is width of microsystem, $h_{m f}$ is height of fiber layer, $h_{m m}$ is height of matrix layer, $h_{m}$ is height of microsystem, $h_{I}$ is height of interface atoms in ET region, $H_{c}$ is height of energy transfer region, $H_{a}$ is height of a mesh, and $L_{a}$ is width of a mesh.

In the design method of ET region, the homogenization method can be extended to mesoscale, ET region, and even microscopic range, which can solve the problem of energy heterogeneous transfer and avoid the complex calculation of reflection and absorption of stress waves. The energy data of macromesosystem obtained by this method is provided to support the establishment of boundary conditions in the microsystem.

\subsection{Microscale}

4.3.1. Microsystem and Its Boundary Conditions. The molecular structure of a bisphenol A epoxy resin is established by using chemical formula and molecular weight (340). And the amorphous structure of 40 epoxy resin molecules (the density is $1.2 \mathrm{~g} / \mathrm{cm}^{3}$ ) is established and optimized. The carbon fiber layer and its supercell are established (the density is $\left.1.78 \mathrm{~g} / \mathrm{cm}^{3}\right)$; further the microsystem $(24.2 \AA \times 24.2 \AA \times$ $61.1 \AA$ ) of the carbon fiber reinforced plastic (CFRP) is built, which combined epoxy resin layer with carbon fiber layer. The microsystem is optimized to guarantee the stable system which has the minimum total energy. Then the relaxation process of this stable system is implemented by using NVT ensemble with a temperature of $298 \mathrm{~K}$, at the time step of $1 \mathrm{fs}$ and the simulation time of $200 \mathrm{ps}$, which can obtain a balanced configuration of microsystem. Furthermore, density of the new microsystem is calculated to prove the accuracy of the system. The calculation density of microsystem is $1.51 \mathrm{~g} / \mathrm{cm}^{3}$ and the fact is $1.49 \mathrm{~g} / \mathrm{cm}^{3}$. The results show that the density error is 1.32 percent. The final microsystem is shown in Figure 9.

4.3.2. Adsorption Energy of Interface. The heating condition of microsystem could be simplified as uniform, in which heat conduction and thermal diffusion are ignored because the

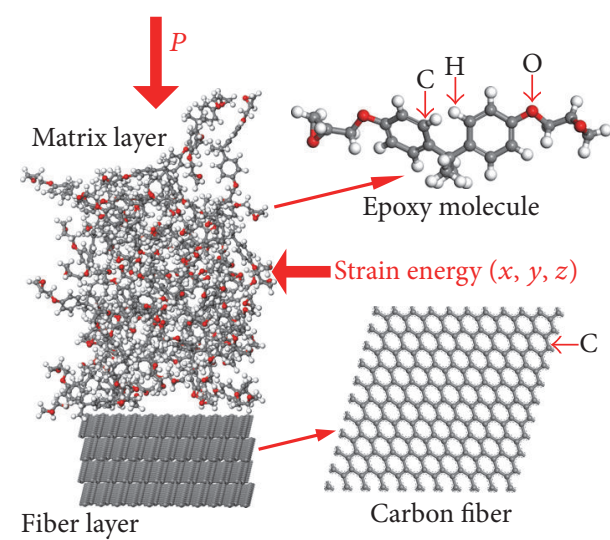

FIgURE 9: The final microsystem and its boundary conditions.

volume of microsystem is small. Here, preheating factor is increased in the microsystem. So the preheating temperature is set to be $40^{\circ} \mathrm{C}(313.15 \mathrm{~K}), 50^{\circ} \mathrm{C}(323.15 \mathrm{~K}), 60^{\circ} \mathrm{C}(333.15 \mathrm{~K})$, and $70^{\circ} \mathrm{C}(343.15 \mathrm{~K})$, respectively. Then 64 groups of $\mathrm{MD}$ simulation parameters can be obtained by linking with 16 groups of FEM conditions. The maximum values of SED in roll nip of number 175 mesh are extracted to import the microsystem by using energy transfer model in (13), (14), and Figure 8. It explains specifically that the energy of microsystem is converted into pressure, and then the pressure can be imported to $x, y$, and $z$ directions by using the system pressurization method (Figure 9), and roller pressure (i.e., compaction force) is exerted to the $z$ direction simultaneously. The microsystem has been stabilized with the time step of $1 \mathrm{fs}$ and simulation time of $200 \mathrm{ps}$ using NPT ensemble. Thus the MD simulation time is set to $30 \mathrm{ps}$. The adsorption process of carbon fiber to epoxy resin is shown in Figure 10.

Fiber and matrix are joined to form a whole composite by the interface of CFRP that acts as a role of passing stress, enhancing compatibility of fibers and matrix. So the mechanical properties of composites can be determined by the strength of fiber/matrix interface to some extent. The adsorption energy (AE) acts as analysis parameter of interfacial adsorption, which is calculated by the following two equations [28]:

$$
E_{\text {total }}=E_{\text {potential }}+E_{\text {kinetic }}+E_{\text {restrain }} \text {, }
$$

where $E_{\text {total }}$ is the total energy of microsystem, $E_{\text {potential }}$ is the potential energy of microsystem, $E_{\text {kinetic }}$ is the kinetic energy of microsystem, and $E_{\text {restrain }}$ is the restrain energy of microsystem and

$$
E_{\text {interaction }}=E_{\text {total }}-\left(E_{\text {surface }}+E_{\text {polymer }}\right),
$$

where $E_{\text {interaction }}$ is the adsorption energy, $E_{\text {surface }}$ is the energy of fiber layer, and $E_{\text {polymer }}$ is the energy of matrix layer.

The results of $\mathrm{AE}$ are calculated by using (15) and (16) under different processing parameters, which are shown in Figure 11.

The calculation results show that all the $\mathrm{AE}$ values are negative, which indicates that the adsorption is an exothermic 


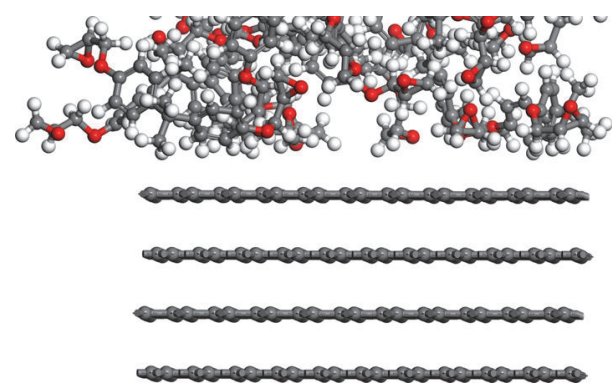

(a)

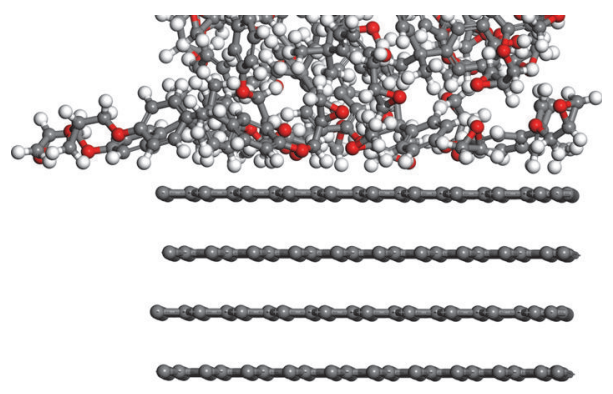

(c)

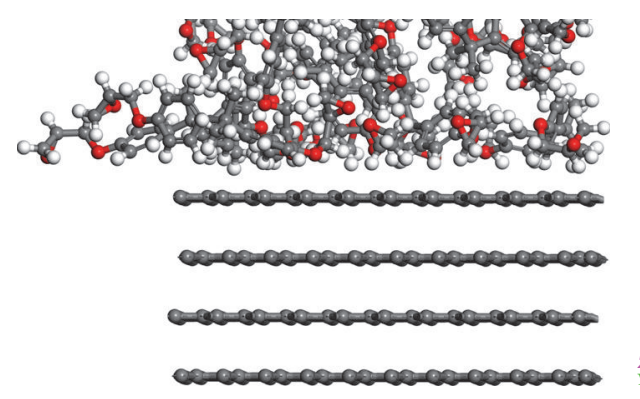

(b)

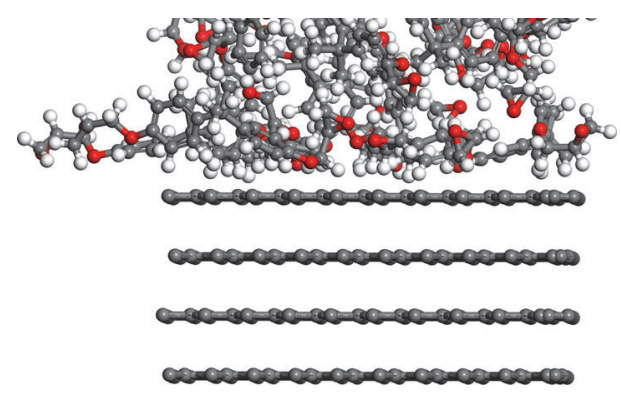

(d)

FIGURE 10: The adsorption process at the compaction force of $250 \mathrm{kPa}$, laying speed of $27 \mathrm{~m} / \mathrm{min}$, and preheating temperature of $333.15 \mathrm{~K}$ : (a) simulation time of $0 \mathrm{ps}$; (b) simulation time of $10 \mathrm{ps}$; (c) simulation time of $20 \mathrm{ps}$; (d) simulation time of $30 \mathrm{ps}$.

process, and the adsorption system is thermodynamically stable under the processing parameters shown in Figure 11. In order to relieve the tensile stress in the thickness direction and further reduce the longitudinal microcracks and delamination defects, strong interfacial adsorption is needed in the selection of the processing parameters. Figure 11 shows that the interfaces have strong adsorption ability at the preheating temperature of $50^{\circ} \mathrm{C}$ to $60^{\circ} \mathrm{C}$ and compaction force of $150 \mathrm{kPa}$ to $250 \mathrm{kPa}$ in high-speed AFP process.

4.3.3. Fluidity of Matrix. Diffusion coefficient (DC) of matrix is calculated by utilizing the mean square displacement (MSD) and Einstein diffusion equation (17) [29], which act as the analysis parameters of fluidity:

$$
\operatorname{MSD}=R(t)=\left\langle|\vec{r}(t)-\vec{r}(0)|^{2}\right\rangle=6 D t,
$$

where $D$ is diffusion coefficient, $r(t)$ is the atomic position in the moment of $t$, and $r(0)$ is the original position of atom.

The evolutions of DC of matrix are calculated by using (17) under different processing parameters, as shown in Figure 12.

In Figure 12, the effect of processing parameters on the fluidity of matrix is significant. The maximum diffusion coefficient is doubled compared to minimum diffusion coefficient under different processing parameters. Moreover, a better fluidity could be represented by a higher diffusion ability of epoxy resin, which bonds the microcracks to a certain extent and further delays the deterioration of the mechanical properties of composite materials. In addition, a good fluidity also is beneficial to reducing defect of pores precipitated by heat volatilization due to movement and releasing of bubbles.

4.4. Multiscale Collaborative Optimization Based on RSM. A reasonable optimization method should be chosen to resolve strong physical coupling fields made by different processing parameters. Several optimization methods such as factorial design, orthogonal design, uniform design, and response surface method are usually used in industrial and agricultural production and scientific research. Response surface method (RSM) is a common method for structure, process design optimization, and reliability analysis, which has the higher precision of regression equation in comparison to orthogonal design and uniform design, and it could obtain the coupling interaction of several factors. Also, it is worth noting that RSM can reflect the interaction between coupling factors directly and have applications in engineering field [30]. In this study, RSM is adopted to solve optimization problem for the reason that there is strong coupling multiple physical parameters and multiscale. In order to choose different levels of parameters randomly, Historical Data Design (HDD) of RSM is used to conduct the second-order design, which can obtain an accurate approximation of a small range around the optimum value. The second-order model of response surface is shown in

$$
y=\beta_{0}+\sum_{i=1}^{k} \beta_{i} x_{i}+\sum_{i=1}^{k} \beta_{i i} x_{i}^{2}+\sum_{i<j}^{k} \beta_{i j} x_{i} x_{j}+\varepsilon .
$$

On the basis of the above methods, response surfaces of different multiscale variables (ALLSE, SED, AE, and DC) to 


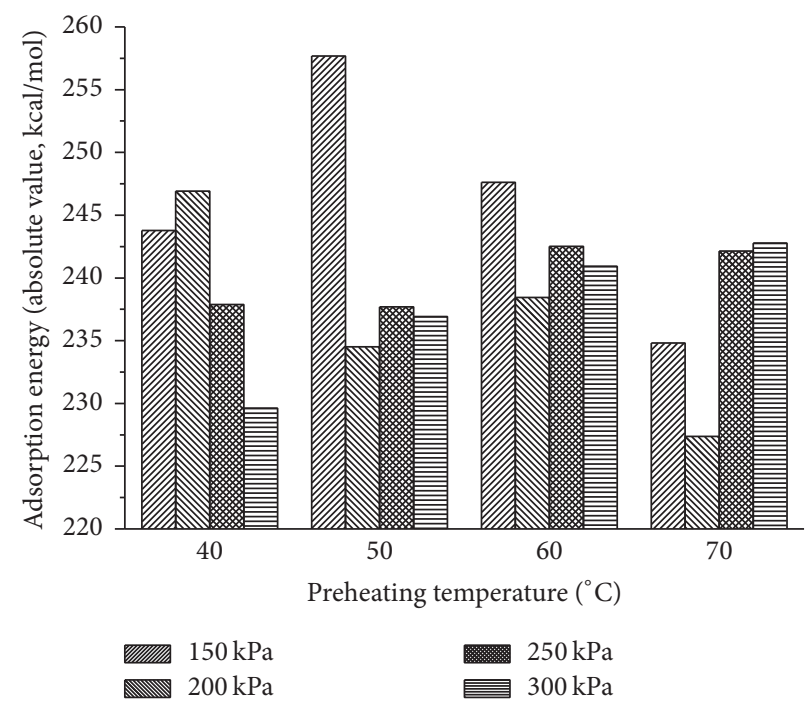

(a)

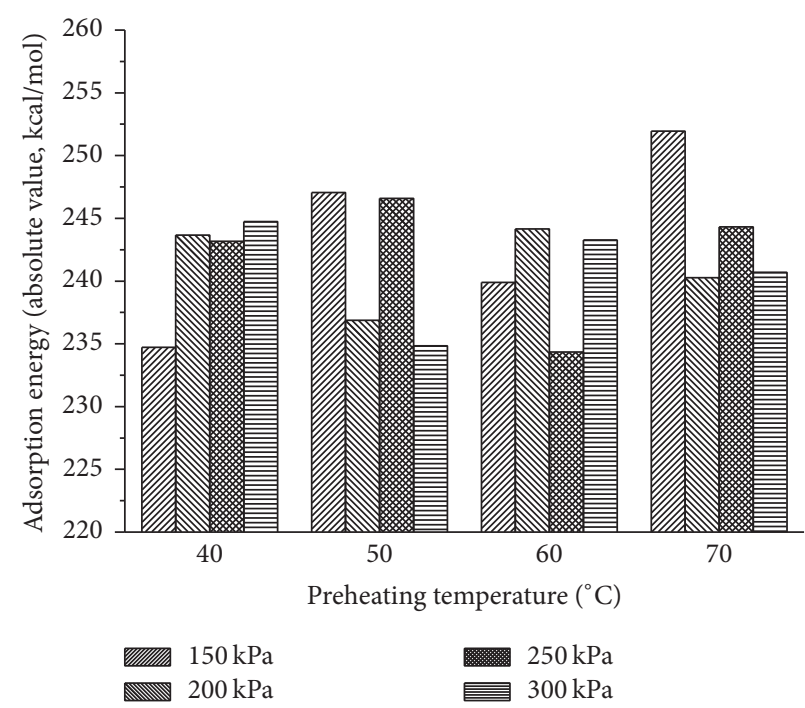

(c)

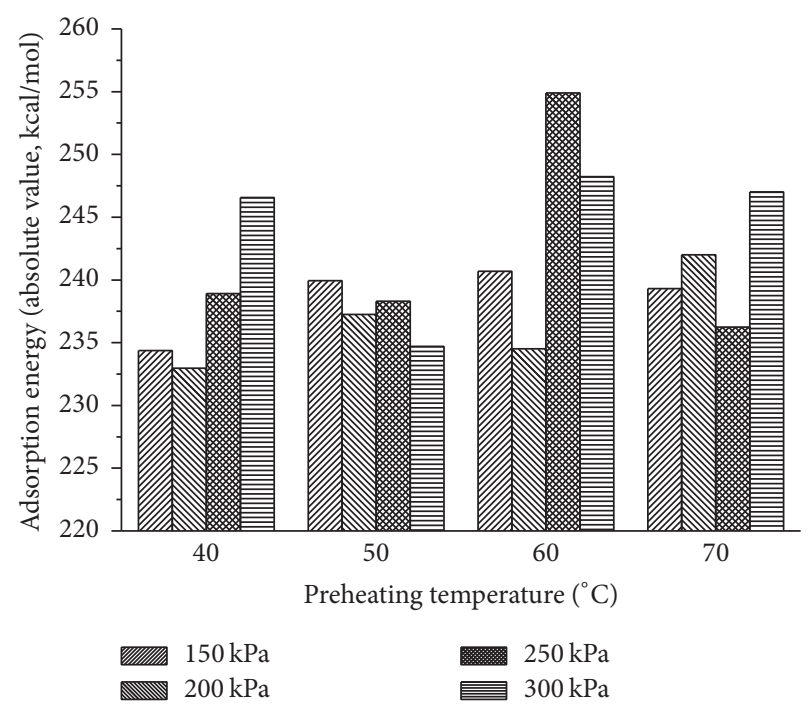

(b)

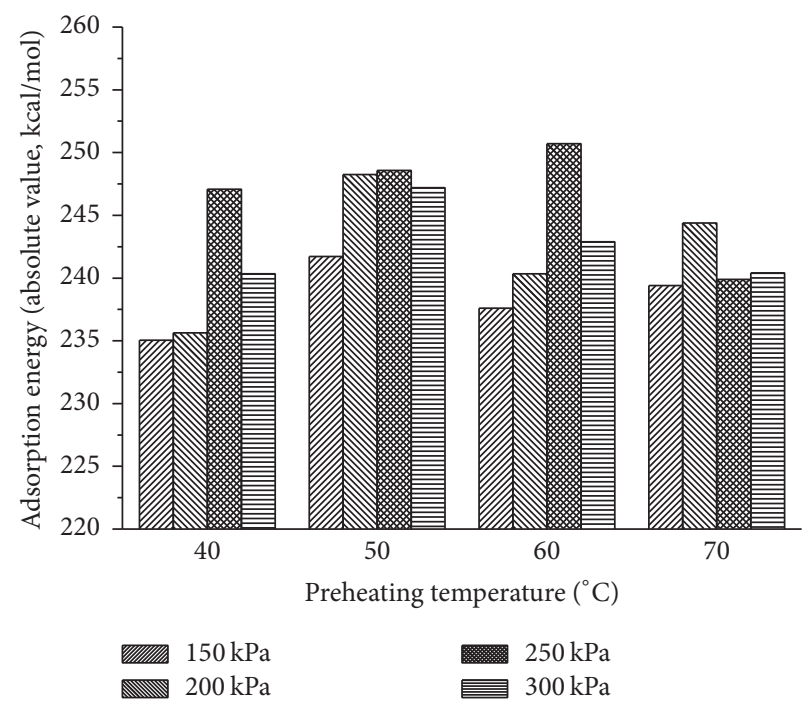

(d)

FIGURE 11: The absolute value of AE under the different processing parameters: (a) laying speed of $27 \mathrm{~m} / \mathrm{min}$; (b) laying speed of $30 \mathrm{~m} / \mathrm{min}$; (c) laying speed of $33 \mathrm{~m} / \mathrm{min}$; (d) laying speed of $36 \mathrm{~m} / \mathrm{min}$.

processing parameters are calculated by using Design-Expert, which are partly shown in Figure 13.

Based on the existing data, multiscale variables corresponding to processing parameters could be predicted by fitting method of RSM, which can reveal the effect laws of processing parameters on multiscale variables clearly. For example, in Figure 13(a), according to fitting surfaces, the laying speed is more than $35 \mathrm{~m} / \mathrm{min}$ or less than $30 \mathrm{~m} / \mathrm{min}$ and the compaction force is more than $280 \mathrm{kPa}$ or less than $180 \mathrm{kPa}$. This range can show the region of smaller values for ALLSE easily. ALLSE reflects physical characteristics of the whole laying tow, which has a high degree of importance. So the minimum value of ALLSE is needed to have an importance of 5 stars. SED, AE, and DC reflect the physical characteristics of the partial laying tow. So the minimum value of SED is set as the importance of 3 stars, and the minimum absolute value of $\mathrm{AE}$ and $\mathrm{DC}$ is required which have the importance of 3 stars. Finally, the desirability of different processing parameters is calculated based on the desirability function and the contour maps of desirability are partly shown in Figure 14.

Two groups of optimum processing parameters ( $F$ is $150.28 \mathrm{kPa}, S$ is $36.25 \mathrm{~m} / \mathrm{min}$, and $T$ is $77.49^{\circ} \mathrm{C}$ and $F$ is $304.76 \mathrm{kPa}, S$ is $27.31 \mathrm{~m} / \mathrm{min}$, and $T$ is $61.97^{\circ} \mathrm{C}$ ) are obtained in terms of the analytical results of desirability. The desirability of these two groups is more than 0.68 . The results indicate that laying speed and compaction force could not be designed too high or too low simultaneously, and preheating temperature 

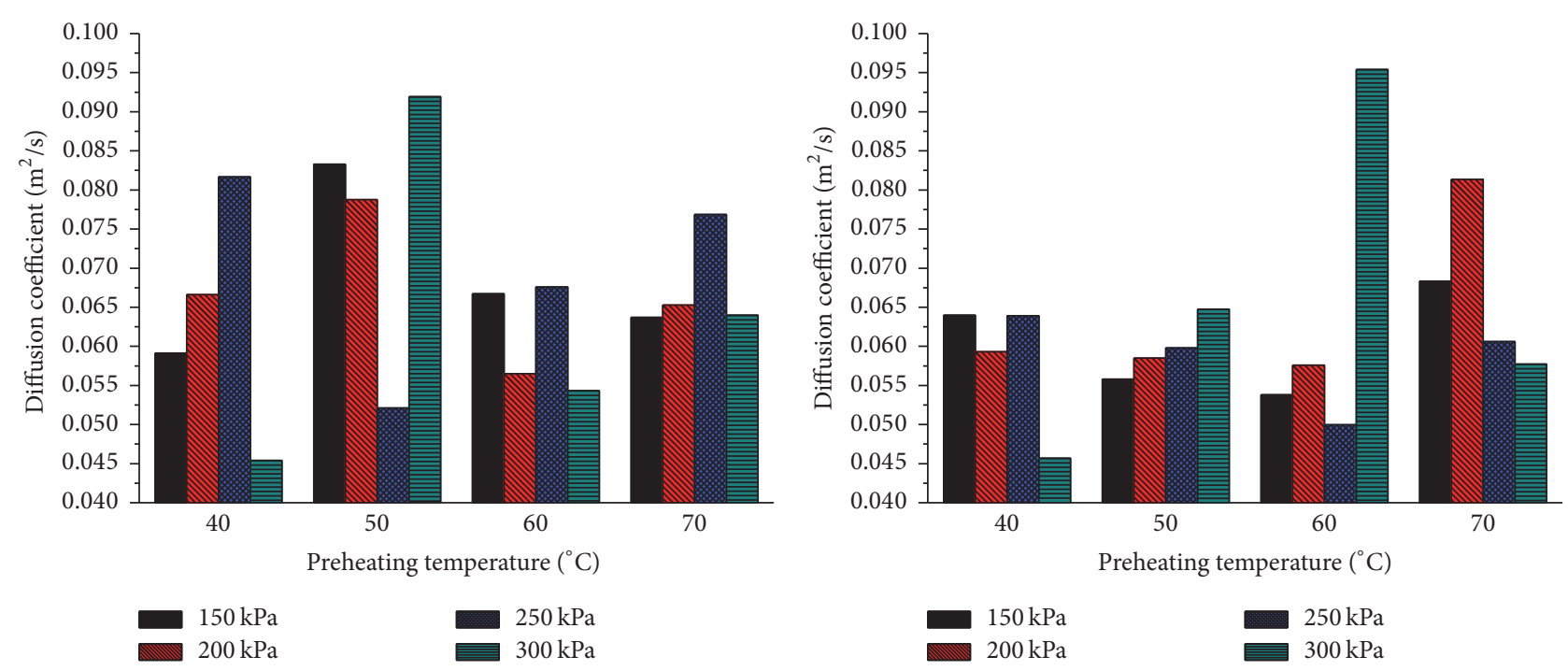

(a)
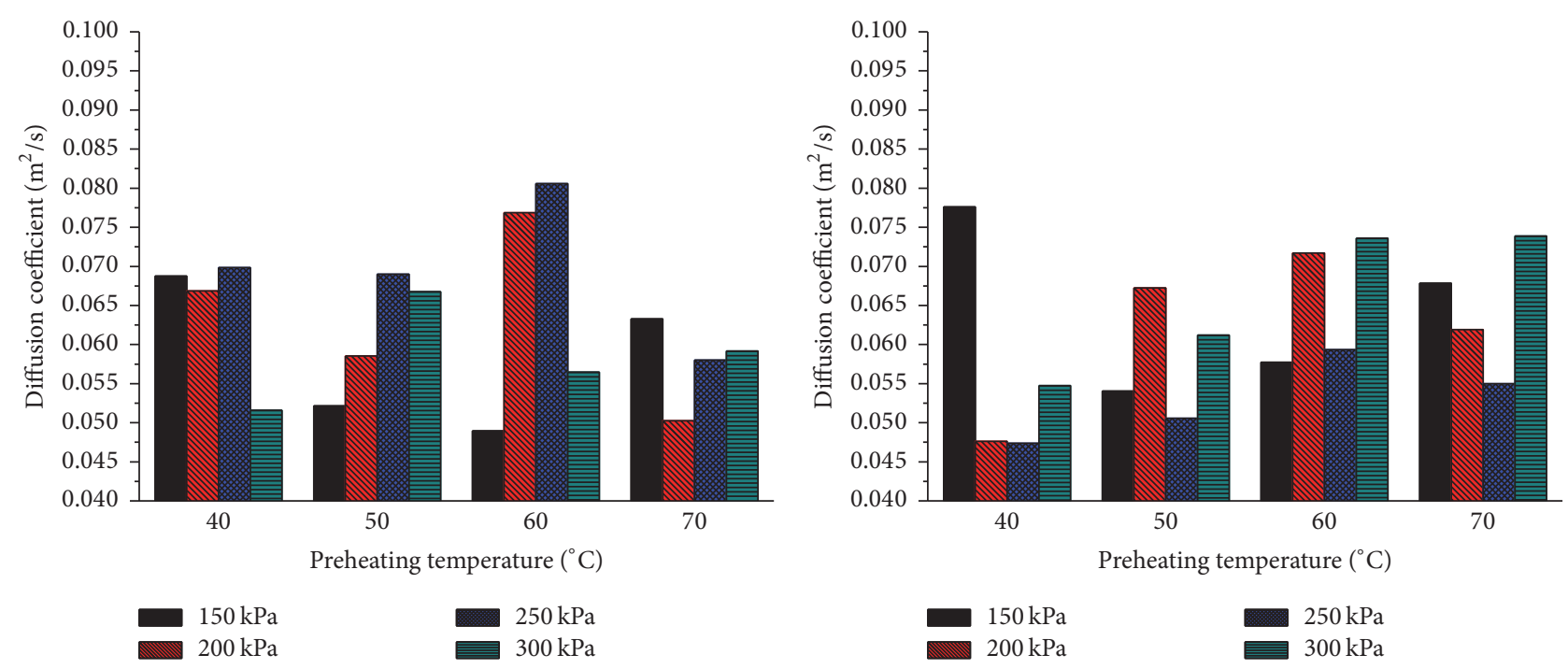

(c)

(d)

FIGURE 12: The DC of epoxy resin in carbon fiber surface under the different processing parameters: (a) laying speed of $27 \mathrm{~m} / \mathrm{min}$; (b) laying speed of $30 \mathrm{~m} / \mathrm{min}$; (c) laying speed of $33 \mathrm{~m} / \mathrm{min}$; (d) laying speed of $36 \mathrm{~m} / \mathrm{min}$.

could be set to be $60^{\circ} \mathrm{C}$ or more. Such measures could reduce the formation probability of defect occurrence of the entire tape and roll nip in high-speed AFP process.

\section{Conclusions}

The multiscale effect of defects in high-speed AFP process should be considered due to special structure and mechanical properties of prepreg tow. This paper optimized processing parameters in terms of multiscale mechanical characteristics of carbon fiber/epoxy prepreg tow and obtained the following conclusions:

(1) ALLSE and SED could be used to evaluate the possibility of the formation of microcracks due to the close relationship between microcracks and strain energy.
And an antisequential hierarchical multiscale collaborative optimization method is proposed, which is suitable for solving the problem of multiscale effect of band-shape prepreg.

(2) Laying speed of about $30-36 \mathrm{~m} / \mathrm{min}$ and compaction force of $300 \mathrm{kPa}$ are found out, which could reduce the peak of ALLSE. The compaction force of $200 \mathrm{kPa}$ seems to enhance stability of SED.

(3) To ensure the higher adsorption ability, preheating temperature of $50^{\circ} \mathrm{C}$ to $60^{\circ} \mathrm{C}$ and compaction force of $150 \mathrm{kPa}$ to $250 \mathrm{kPa}$ are preferred.

(4) Two groups of optimal processing parameters (i.e., $F$ is $150.28 \mathrm{kPa}, S$ is $36.25 \mathrm{~m} / \mathrm{min}$, and $T$ is $77.49^{\circ} \mathrm{C}$ and $F$ is $304.76 \mathrm{kPa}, S$ is $27.31 \mathrm{~m} / \mathrm{min}$, and $T$ is $61.97^{\circ} \mathrm{C}$ ) are obtained based on RSM, and their desirability is more 


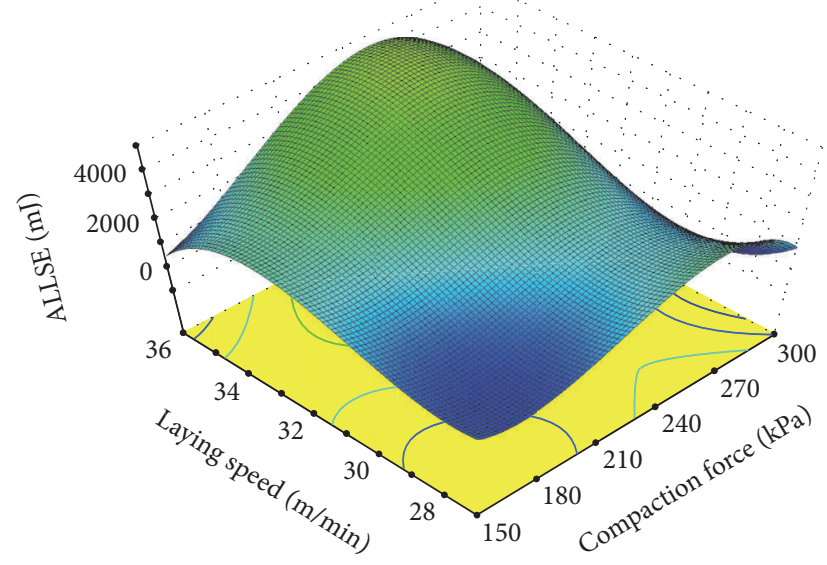

(a)

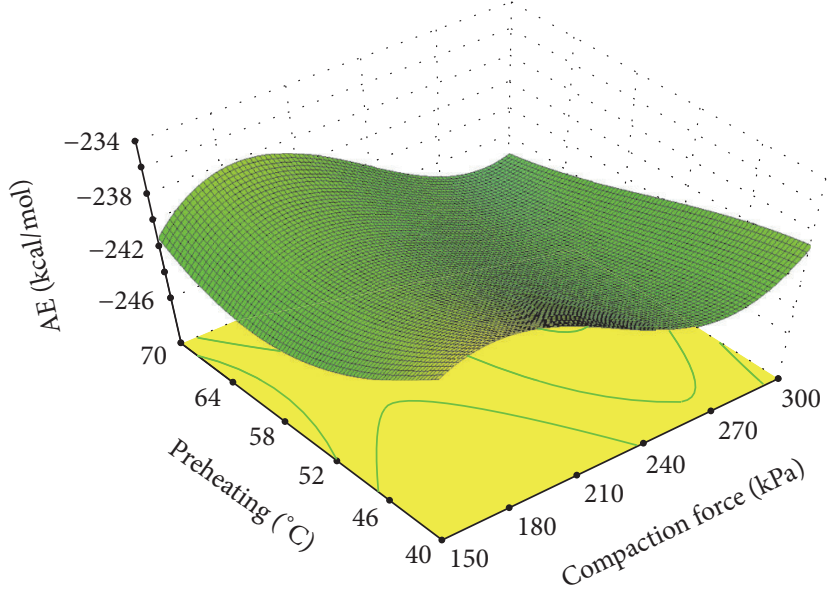

(c)

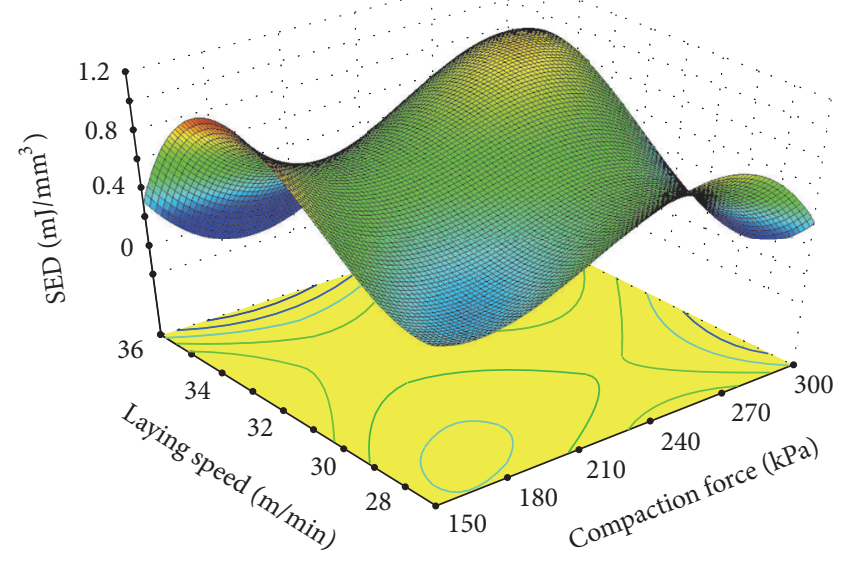

(b)

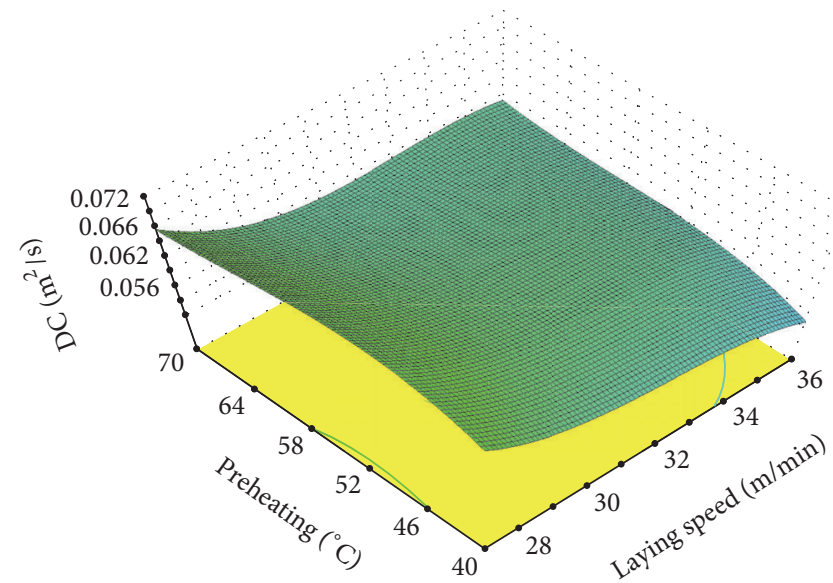

(d)

FIGURE 13: The response surfaces of multiscale variables to processing parameters: (a) the response surface of ALLSE to laying speed and compaction force; (b) the response surface of SED to laying speed and compaction force; (c) the response surface of AE to preheating temperature and compaction force; (d) the response surface of preheating temperature and laying speed.

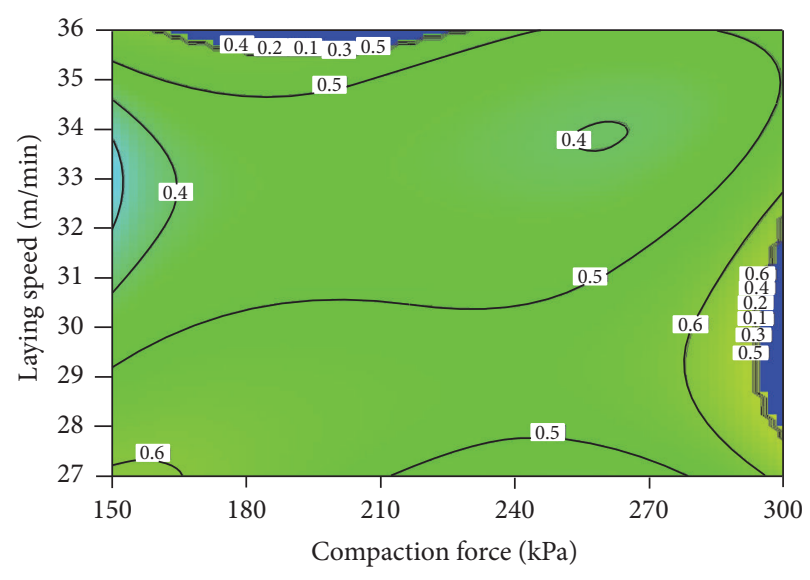

(a)

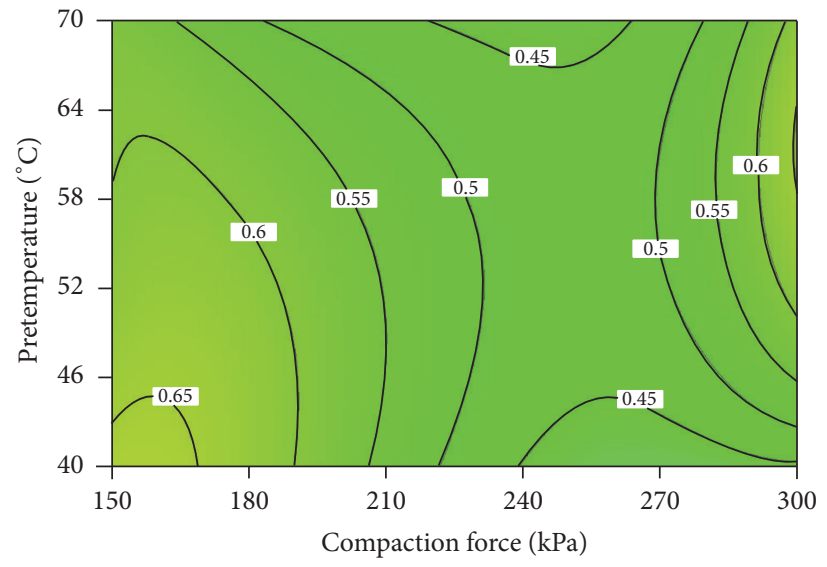

(b)

FIGURE 14: The desirability analytical results: (a) compaction force and laying speed; (b) pretemperature and compaction force. 
than 0.68 , which could trade off the coupling conflict of processing parameters.

Future work includes developing experiments to verify the accuracy of two groups of optimal processing parameters which can reduce the formation of microcracks, and curing techniques should also be taken into account for improving the theoretical model.

\section{Competing Interests}

The authors declare that they have no competing interests.

\section{Acknowledgments}

This study is financially supported by National Science and Technology Major Projects of China (2014ZX04001091).

\section{References}

[1] X. Li, Z. Guan, L. Liu, and Z. Li, "Composite multiscale failure criteria and damage evolution," Acta Materiae Compositae Sinica, vol. 30, no. 2, pp. 152-158, 2013.

[2] C. G. Grant, "Fiber placement process utilization within the world wide aerospace industry," SAMPE Journal, vol. 36, no. 4, pp. 45-50, 2000.

[3] D. H.-J. A. Lukaszewicz, C. Ward, and K. D. Potter, "The engineering aspects of automated prepreg layup: history, present and future," Composites Part B: Engineering, vol. 43, no. 3, pp. 997-1009, 2012.

[4] Y. L. Bai, H. Y. Wang, M. F. Xia, and F. J. Ke, "Statistical mesomechanics of solid, linking coupled multiple space and time scales," Applied Mechanics Reviews, vol. 58, no. 1-6, pp. 372-388, 2005.

[5] M. Marder and J. Fineberg, "How things break," Physics Today, vol. 49, no. 9, pp. 24-29, 1996.

[6] B. Berisha, C. Raemy, C. Becker, M. Gorji, and P. Hora, "Multiscale modeling of failure initiation in a ferritic-pearlitic steel," Acta Materialia, vol. 100, pp. 191-201, 2015.

[7] H. Liu, X. Y. Sun, Y. J. Xu, and X. H. Chu, "A hierarchical multilevel finite element method for mechanical analyses of periodical composite structures," Composite Structures, vol. 131, pp. 115-127, 2015.

[8] S.-I. Sakata and I. Torigoe, "A successive perturbation-based multiscale stochastic analysis method for composite materials," Finite Elements in Analysis and Design, vol. 102-103, pp. 74-84, 2015.

[9] A. Visrolia and M. Meo, "Multiscale damage modelling of 3D weave composite by asymptotic homogenisation," Composite Structures, vol. 95, pp. 105-113, 2013.

[10] B. A. Jaramillo, R. Nielsen, R. Abrol et al., "First-principlesbased multiscale, multiparadigm molecular mechanics and dynai mics methods for describing complex chemical processes," in Multiscale Molecular Methods in Applied Chemistry, vol. 307, pp. 1-42, 2012.

[11] P. P. Parlevliet, H. E. N. Bersee, and A. Beukers, "Residual stresses in thermoplastic composites: a study of the literature. Part III: Effects of thermal residual stresses," Composites Part A: Applied Science and Manufacturing, vol. 38, no. 6, pp. 1581-1596, 2007.
[12] G. Han, Z. D. Guan, X. Li, W. Zhang, and S. Y. Du, "Microscopic progressive damage simulation of unidirectional composite based on the elastic-plastic theory," Journal of Reinforced Plastics \& Composites, vol. 34, no. 3, pp. 232-247, 2015.

[13] A. Sayyidmousavi, H. Bougherara, and Z. Fawaz, "A multiscale approach for fatigue life prediction of polymer matrix composite laminates," Journal of Reinforced Plastics and Composites, vol. 34, no. 13, pp. 1099-1109, 2015.

[14] W. J. B. Grouve, L. L. Warnet, B. Rietman, H. A. Visser, and R. Akkerman, "Optimization of the tape placement process parameters for carbon-PPS composites," Composites Part A: Applied Science and Manufacturing, vol. 50, pp. 44-53, 2013.

[15] S. Tumkor, N. Turkmen, C. Chassapis, and S. Manoochehri, "Modeling of heat transfer in thermoplastic composite tape layup manufacturing," International Communications in Heat and Mass Transfer, vol. 28, no. 1, pp. 49-58, 2001.

[16] F. O. Sonmez and M. Akbulut, "Process optimization of tape placement for thermoplastic composites," Composites Part A: Applied Science and Manufacturing, vol. 38, no. 9, pp. 2013-2023, 2007.

[17] T. Aized and B. Shirinzadeh, "Robotic fiber placement process analysis and optimization using response surface method," International Journal of Advanced Manufacturing Technology, vol. 55, no. 1-4, pp. 393-404, 2011.

[18] Z.-G. Wang, M. Li, W. Wu, and N.-G. Liang, "Strain regularity and stiffness tensor of reinforcers in dense particle reinforced composites," Chinese Journal of Aeronautics, vol. 14, no. 4, pp. 217-221, 2001.

[19] A. Puck and H. Schürmann, "Failure analysis of FRP laminates by means of physically based phenomenological models," Composites Science and Technology, vol. 62, no. 12-13, pp. 1633-1662, 2002.

[20] J. Q. Broughton, F. F. Abraham, N. Bernstein, and E. Kaxiras, "Concurrent coupling of length scales: methodology and application," Physical Review B, vol. 60, no. 4, pp. 2391-2403, 1999.

[21] R. E. Rudd and J. Q. Broughton, "Concurrent coupling of length scales in solid state systems," Physica Status Solidi (B) Basic Research, vol. 217, no. 1, pp. 251-291, 2000.

[22] D. L. McDowell, H.-J. Choi, J. Panchal, R. Austin, J. Allen, and F. Mistree, "Plasticity-related microstructure-property relations for materials design," Key Engineering Materials, vol. 340-341, pp. 21-30, 2007.

[23] G. B. Olson, "Computational design of hierarchically structured materials," Science, vol. 277, no. 5330, pp. 1237-1242, 1997.

[24] F. F. Abraham, J. Q. Broughton, N. Bernstein, and E. Kaxiras, "Spanning the continuum to quantum length scales in a dynamic simulation of brittle fracture," Europhysics Letters, vol. 44, no. 6, pp. 783-787, 1998.

[25] H. S. Park and W. K. Liu, "An introduction and tutorial on multiple-scale analysis in solids," Computer Methods in Applied Mechanics and Engineering, vol. 193, no. 17-20, pp. 1733-1772, 2004.

[26] L. E. Shilkrot, R. E. Miller, and W. A. Curtin, "Multiscale plasticity modeling: coupled atomistics and discrete dislocation mechanics," Journal of the Mechanics and Physics of Solids, vol. 52, no. 4, pp. 755-787, 2004.

[27] R. E. Miller and E. B. Tadmor, "The Quasicontinuum Method: overview, applications and current directions," Journal of Computer-Aided Materials Design, vol. 9, no. 3, pp. 203-239, 2002. 
[28] M. H. Wong, M. Paramsothy, X. J. Xu, Y. Ren, S. Li, and K. Liao, "Physical interactions at carbon nanotube-polymer interface," Polymer, vol. 44, no. 25, pp. 7757-7764, 2003.

[29] C. Ding and Y. Fan, "Measurement of diffusion coefficients of air in silicone oil and in hydraulic oil," Chinese Journal of Chemical Engineering, vol. 19, no. 2, pp. 205-211, 2011.

[30] N. N. Yang, P. K. Das, and X. L. Yao, "Application of response surface method for reliability analysis of stiffened laminated plates," Ships and Offshore Structures, vol. 10, no. 6, pp. 653-659, 2015. 

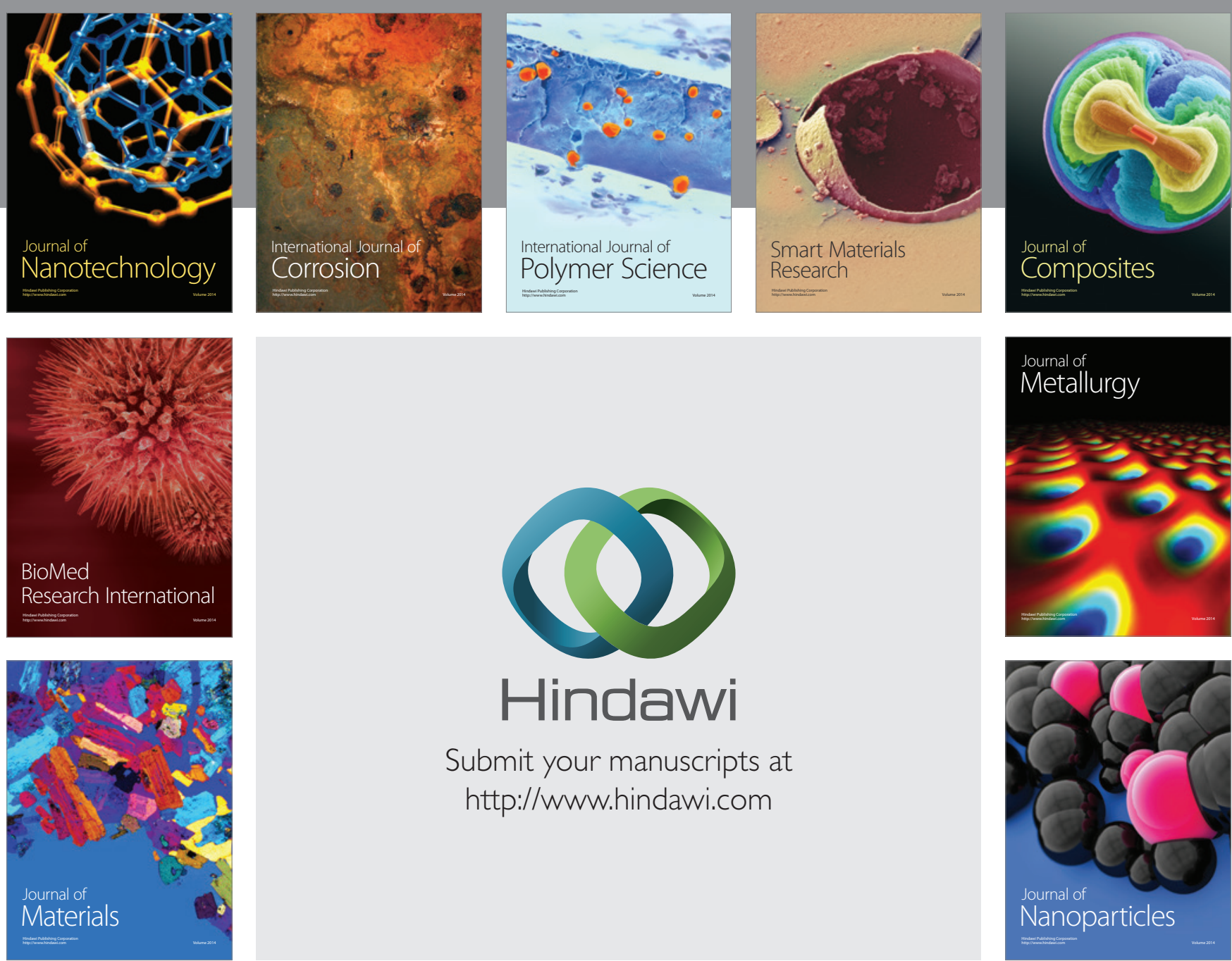

\section{Hindawi}

Submit your manuscripts at

http://www.hindawi.com

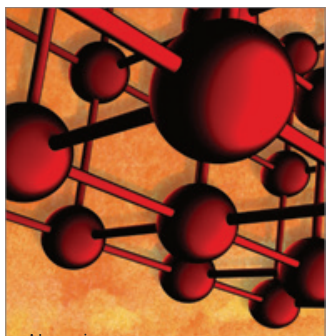

Materials Science and Engineering
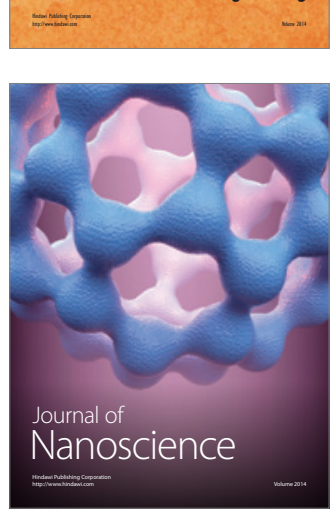
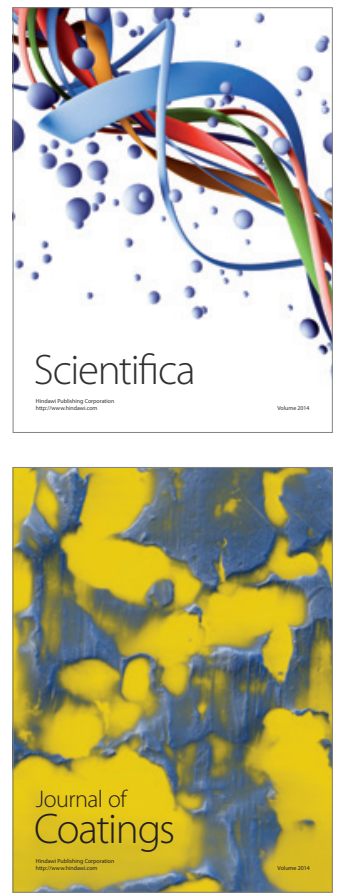
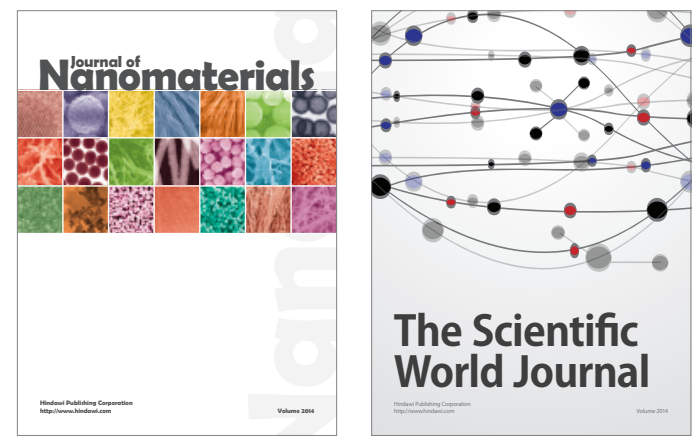

The Scientific World Journal
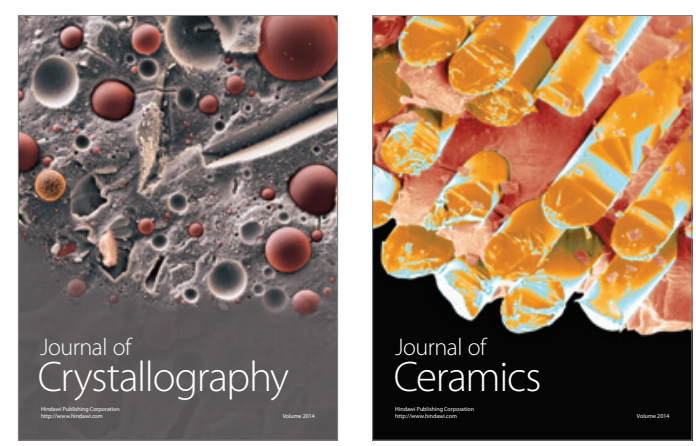
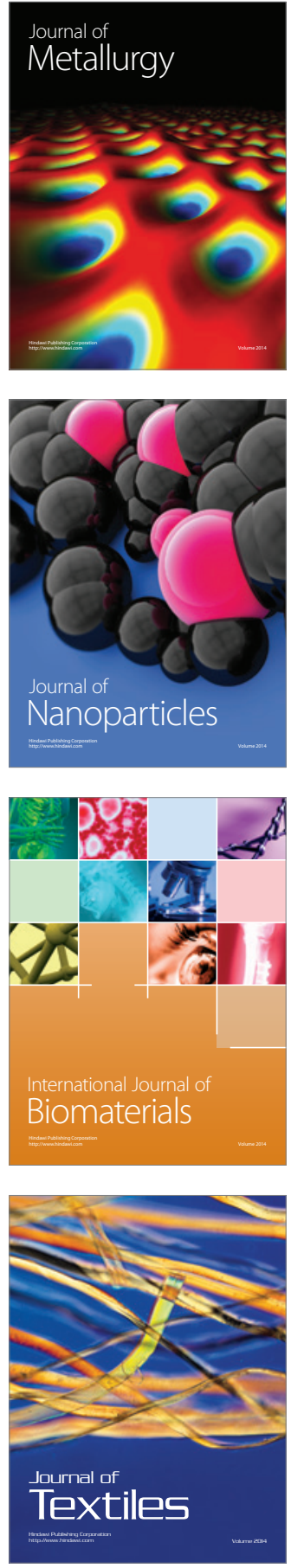